\title{
Effect of Chromium-Gold and Titanium-Titanium Nitride-Platinum-Gold Metallization on Wire/Ribbon Bondability
}

\author{
Jianbiao Pan, Member, IEEE, Robert M. Pafchek, Frank F. Judd, and Jason B. Baxter
}

\begin{abstract}
Gold metallization on wafer substrates for wire/ribbon bond applications requires good bond strength to the substrate without weakening the wire/ribbon. This paper compares the ribbon bondability of $\mathrm{Cr}-\mathrm{Au}$ and $\mathrm{Ti}-\mathrm{TiN}-\mathrm{Pt}-\mathrm{Au}$ metallization systems for an optoelectronic application. Both Chromium and Titanium are used to promote adhesion between semiconductor substrates and sputtered gold films. However, both will be oxidized if they diffuse to the gold surface and result in the degradation of the wire/ribbon bondability. Restoring bondability by ceric ammonium nitrate (CAN) etch was investigated. Experiments were conducted to investigate the effect of $\mathrm{Cr}-\mathrm{Au}$ and $\mathrm{Ti}-\mathrm{TiN}-\mathrm{Pt}-\mathrm{Au}$, annealing, and CAN etch processes, on $25.4 \times 254 \mu \mathrm{m}(1 \times 10 \mathrm{mil})$ ribbon bonding. All bonds were evaluated by noting pull strengths and examining specific failure modes. The results show that there is no significant difference in bondability between $\mathrm{Cr}-\mathrm{Au}$ and $\mathrm{Ti}-\mathrm{TiN}-\mathrm{Pt}-\mathrm{Au}$ before the annealing process. At this point, excellent bond strength can be achieved. However, wire/ribbon bondability of $\mathrm{Cr}-\mathrm{Au}$ degraded after the wafers were annealed. The experimental results also show that a CAN etch can remove $\mathrm{Cr}$ oxide, and that the improvement in wire/ribbon bondability of $\mathrm{Cr}-\mathrm{Au}$ depends on the $\mathrm{CAN}$ etch time. It is further demonstrated that the same annealing process does not have a significant effect on the bondability of Ti-TiN-Pt-Au metallization on the same type substrate materials. Auger electron spectroscopy was used to investigate the causes fothe difference in bondability between these two metallizations.
\end{abstract}

Index Terms-Chromium, gold, metallization, ribbon bonding, titanium, wire bonding.

\section{INTRODUCTION}

$\mathbf{F}$ UTURE developments in silicon waveguide devices such as thermooptics require multilevel metallization in addition to the deposition of doped silica layers. There are several available metallization schemes under consideration that could meet the requirements for resistance and stability. The metallization systems investigated in this paper were Chromium-Gold $(\mathrm{Cr}-\mathrm{Au})$ and Titanium-Titanium Nitride-Platinum/Gold (Ti-TiN-Pt-Au).

Manuscript received July 30, 2004; revised November 30, 2005 and February 1, 2006. This paper was presented at the 29th IEEE International Electronics Manufacturing Technology Symposium, San Jose, CA, July 13-16, 2004.

J. Pan is with the Department of Industrial and Manufacturing Engineering, California Polytechnic State University, San Luis Obispo, CA 93407 USA (e-mail: pan@calpoly.edu)

R.M. Pafchek is with Agere Systems, Breinigsville, PA 18031 USA.

F.F. Judd, retired, was with Agere Systems, Breinigsville, PA 18031 USA.

J. B. Baxter is with the Chemistry Department, Yale University, New Haven, CT 06520 USA.

Digital Object Identifier 10.1109/TADVP.2006.884774
In the $\mathrm{Cr}-\mathrm{Au}$ metallization scheme, $\mathrm{Cr}$ is used to promote adhesion between the semiconductor substrate and the sputtered gold film because the gold generally will not form a mechanical bond with the substrate. However, $\mathrm{Cr}$ can diffuse through grain boundary up to the gold surface after annealing and then oxidize to form $\mathrm{Cr}_{2} \mathrm{O}_{3}$ [1]. The $\mathrm{Cr}_{2} \mathrm{O}_{3}$ on Au surface will degrade wire/ribbon bondability. For example, thermocompression bondability of 3- $\mu \mathrm{m}$-thick Au films degraded after heating $\mathrm{Cr}-\mathrm{Au}$ films for $2 \mathrm{~h}$ at $250^{\circ} \mathrm{C}$ [2] or for $2 \mathrm{~h}$ at $300^{\circ} \mathrm{C}$ [3]. Higher temperature can increase $\mathrm{Cr}$ diffusion speed and reduce the diffusion time to Au surface significantly [1]. It has been shown that these bonding problems can be eliminated either by etching the gold surface using $\mathrm{KI}+\mathrm{I} 2$ so that the attached oxide is removed, or by etching with ceric ammonium nitrate (CAN) to remove the oxides without affecting the gold [3].

Titanium (Ti) is often used as a glue layer between the semiconductor substrate and a conductor layer such as Au [4]. In the Ti-Au bilayer thin film, interdiffusion will happen and form $\mathrm{TiAu}_{2}, \mathrm{TiAu}$, and $\mathrm{Ti}_{3} \mathrm{Au}$ during annealing at over $250{ }^{\circ} \mathrm{C}$ [5]. To prevent the interdiffusion between $\mathrm{Ti}$ and $\mathrm{Au}$, a third metal Platinum (Pt) or Palladium (Pd) is commonly used as a barrier layer [4], [6]. In the Ti-Pt-Au metallization scheme, however, Ti can diffuse to the Pt layer through grain boundaries as well. The diffusion process model proposed by Tisone and Drobek [4] in which Ti diffuses along Pt grain boundaries and forms TiPt intermetallic compounds was verified by Garceau $e t$ al. [7]. Garceau et al. [7] further showed that the incorporation of a thin $(150 \AA)$ layer of Titanium Nitride (TiN) between the Ti (850 to $1000 \AA)$ and Pt (1500 to $2000 \AA)$ layers could inhibit the formation of TiPt intermetallic compounds effectively. Thompson et al. [8] reported the bondability problems associated with Ti-Pt-Au metallization. Based on the authors' knowledge, no study was yet published on the Ti-TiN-Pt-Au bondability.

The purpose of this study was to compare the ribbon bondability of $\mathrm{Cr}-\mathrm{Au}$ and $\mathrm{Ti}-\mathrm{TiN}-\mathrm{Pt}-\mathrm{Au}$ metallization systems for an optoelectronic application. The specific metallization systems were $2000 / 6000 \mathrm{Cr}-\mathrm{Au}(2000 \AA$ of Chromium and $6000 \AA$ of Gold on the wafer surface), and 1000/250/2000/6000 Ti-TiN-Pt-Au (1000 $\AA$ of Titanium, $250 \AA$ of Titanium Nitride, $2000 \AA$ of Platinum, and $6000 \AA$ of Gold on the wafer).

\section{EXPERIMENTAL DESIGN AND ANALYSIS}

Two experiments were designed to examine the effects of these two metallization schemes on ribbon bondability. The first experiment focuses on metallization without annealing. 
TABLE I

PROCESS PARAMETERS

\begin{tabular}{|l|c|c|}
\hline & $1^{\text {st }}$ bond & $2^{\text {nd }}$ bond \\
\hline Force (grams) & 120 & 130 \\
\hline Time (msec.) & 500 & 500 \\
\hline Ultrasonic Power & 60 & 60 \\
\hline Ultrasonic Mode & voltage & voltage \\
\hline Ultrasonic Type & ramp & ramp \\
\hline Delay time (msec.) & 250 & 250 \\
\hline Workholder temp. & \multicolumn{2}{|c|}{$150^{\circ} \mathrm{C}$} \\
\hline
\end{tabular}

TABLE II

FAILURe Modes AND Pull StREnGths From ExPERIMENT 1

\begin{tabular}{|l|l|c|c|c|c|c|c|}
\hline \multirow{2}{*}{} & \multicolumn{3}{|c|}{ Failure mode for 100 ribbons } & \multicolumn{2}{c|}{$\begin{array}{c}\text { Pull strength for } \\
100 \text { ribbons }\end{array}$} \\
\cline { 3 - 8 } \multicolumn{2}{|c|}{} & $\begin{array}{c}\text { Heel } \\
\text { break }\end{array}$ & $\begin{array}{c}\text { Foot } \\
\text { lift }\end{array}$ & $\begin{array}{c}\text { Non- } \\
\text { stick }\end{array}$ & $\begin{array}{c}\text { Ribbon } \\
\text { break }\end{array}$ & $\begin{array}{c}\text { Average } \\
\text { (grams) }\end{array}$ & Stdev \\
\hline $\begin{array}{l}\text { Without UV } \\
\text { cleaning }\end{array}$ & $\mathrm{Cr} / \mathrm{Au}$ & $93 \%$ & $2 \%$ & 0 & $5 \%$ & 211.5 & 7.6 \\
\cline { 2 - 8 } & $\mathrm{Ti} / \mathrm{TiN} / \mathrm{Pt} / \mathrm{Au}$ & $97 \%$ & 0 & 0 & $3 \%$ & 210.3 & 6.6 \\
\hline $\begin{array}{l}\text { UV cleaning } \\
10 \text { min. }\end{array}$ & $\mathrm{Cr} / \mathrm{Au}$ & $98 \%$ & $1 \%$ & 0 & $1 \%$ & 206.8 & 9.9 \\
\cline { 2 - 9 } & $\mathrm{Ti} / \mathrm{TiN} / \mathrm{Pt} / \mathrm{Au}$ & $96 \%$ & 0 & 0 & $4 \%$ & 214.6 & 6.2 \\
\hline
\end{tabular}

The second experiment includes effects of the annealing and the CAN etch. Samples for both experiments were prepared by dicing wafers and mounting them on a suitable metal package with epoxy so that the wafers were clamped well during bonding.

The bondability was based on evaluations using gold ribbon $25.4 \mu \mathrm{m}(1 \mathrm{mil})$ thick and $254 \mu \mathrm{m}(10 \mathrm{mil})$ wide. The bondability of wide gold ribbon was believed to be more sensitive to the surface contamination than a round $25.4-\mu \mathrm{m}$ (1-mil) diameter or 33- $\mu \mathrm{m}$ (1.3-mil) diameter wire due to larger bonding area, based on the authors' experience. Ribbon samples were tested destructively on a Dage pull tester. Pull strengths and failure modes were recorded. The ribbon bonds were made using an automated Palomar 2470 V bonder using row bond mode.

\section{A. Experiment 1}

The first experiment was constructed from wafers without annealing. A two factor two level factorial design was selected in this experiment. The samples were split into four cells: $\mathrm{Cr}-\mathrm{Au}$, one with $10 \mathrm{~min}$ of UV ozone cleaning and one without; and Ti-TiN-Pt-Au, one with 10 min of UV ozone cleaning and one without. The purpose of UV ozone cleaning is to remove the surface contamination from wafer surfaces.

To achieve the highest pull strength, bonding process parameters were optimized and are shown in Table I. Each package was bonded with 100 ribbons. Thermal cycling was used to evaluate the reliability of the ribbon bonds. After thermal cycling $\left(0{ }^{\circ} \mathrm{C}-85^{\circ} \mathrm{C}\right.$, four cycles $)$, all ribbons were pulled. The thermal cycle parameters of 0 to $85^{\circ} \mathrm{C}$, and four cycles, are representative of typical manufacturing stresses required in the assembly of optoelectronic devices. Pull strengths and failure modes are documented in Table II.

The failure modes indicated in Table II are typical of those seen in developing a good quality ribbon bonding process for optoelectronic devices. The "nonstick" failure occurs when the bonding process is insufficient to achieve adhesion of the ribbon to the substrate surface. When this happens, the ribbon bonder itself, during the act of ribbon tear, lifts the foot of the ribbon off

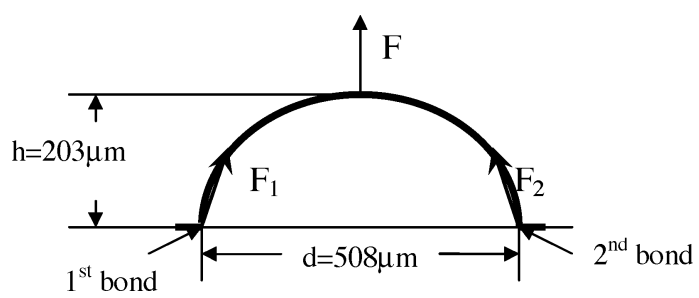

Fig. 1. Ribbon bonds pull test geometry.

the substrate surface. The "foot lift" failure occurs when the foot of the ribbon is pulled away from the substrate surface during the pull testing, but the ribbon stuck to the substrate surface before the pull test. The "heel break" occurs at the interface between the ribbon foot and the ribbon, and the foot of the wire still remains at the bond pad after destructive pull test. The "ribbon break" is a failure that occurs at any point in the ribbon above the heel during the pull testing. In terms of ribbon bondability performance, heel break and ribbon break are desirable failure modes, while foot lift and nonstick are undesirable failure modes.

Bond pull strength testing was accomplished in accordance with MIL-STD-883E, method 2011.7. Per MIL-STD-883E, the minimum acceptable bond pull strength for a $25.4 \mu \mathrm{m} \times 254 \mu \mathrm{m}$ ( $1 \mathrm{mil} \times 10 \mathrm{mil}$ ) gold ribbon bonds is $20 \mathrm{~g}$. Since pull strength is known to be loop dependent [1], all loop heights in this study were made at $203 \mu \mathrm{m}$ ( $8 \mathrm{mil}$ ), and loop lengths were made at $508 \mu \mathrm{m}$ (20 mil). The two bonds were at the same level on wafer surface and the pull hook was at the center of the loop as shown in Fig. 1. The tensile strength in the first bond and the second bond can be calculated according the following equation [1]:

$$
F_{1}=F_{2}=\frac{F}{2} \sqrt{1+\left(\frac{d}{2 h}\right)^{2}}
$$

where $F_{1}$ and $F_{2}$ is the tensile strength at the first bond and second bond, respectively, $F$ is the pull strength at the hook, $h$ is the loop height, and $d$ is the distance between the first bond and the second bond. The loop profile used in this study results in a break strength at the first bond being the same as the break strength at the second bond. These break strengths are about 0.8 times of the pull strength at the hook.

Table II shows that there is no statistically significant difference in ribbon bondability between the $\mathrm{Cr}-\mathrm{Au}$ and the Ti-TiN-Pt-Au metallization systems without annealing. Moreover, both metallization systems without annealing provide excellent bondability. The average pull strength is more than 18 sigma above the minimum acceptable bond pull strength defined by MIL-STD-883E. Although Table II shows that there were $2 \%$ and $1 \%$ foot lifts on $\mathrm{Cr}-\mathrm{Au}$ metallization without UV Ozone cleaning, and UV Ozone cleaning for $10 \mathrm{~min}$, respectively, the bonding process could be adjusted to eliminate this undesired failure mode. Generally speaking, there is a correlation between bond strength and wire/ribbon deformation [9]. Increasing bonding ultrasonic power can deform wire/ribbon more, which tends to make stronger bond between bond foot and the substrate [9]. However, excessively deformed bonds will weaken the heel, a critical region in the bond, and result in low bond strength. The UV ozone clean did not improve 


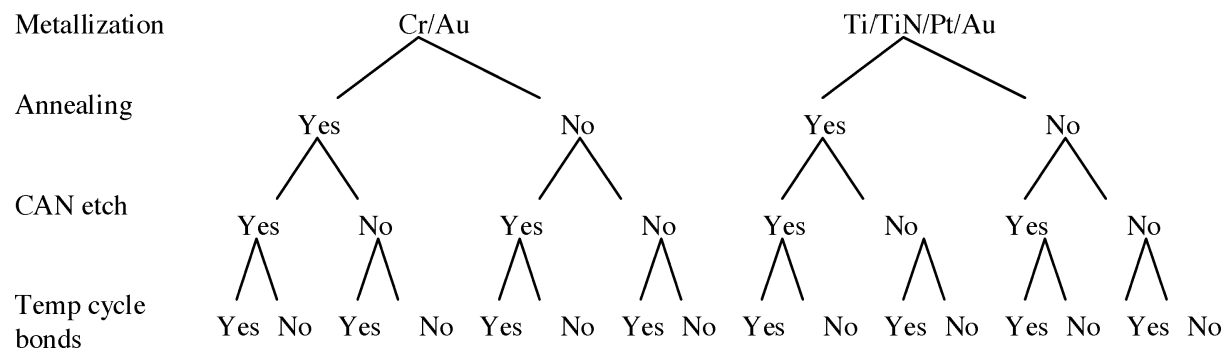

Fig. 2. Experiment 2 design.

TABLE III

FAILURE MODES AND PULL STRENGTHS OF EXPERIMENT 2

\begin{tabular}{|c|c|c|c|c|c|c|c|c|c|}
\hline & & & & & Failu & mode & & Pull str & ngth \\
\hline & Metallization & Annealed & C.A.N. & $\begin{array}{l}\text { Heel } \\
\text { break }\end{array}$ & $\begin{array}{c}\text { Foot } \\
\text { lift }\end{array}$ & $\begin{array}{l}\text { Non- } \\
\text { stick }\end{array}$ & $\begin{array}{c}\text { Ribbon } \\
\text { break }\end{array}$ & $\begin{array}{c}\text { Average } \\
\text { (grams) }\end{array}$ & Stdev \\
\hline \multirow{8}{*}{$\begin{array}{l}\text { Before } \\
\text { Temp. } \\
\text { Cycle }\end{array}$} & $\mathrm{Cr} / \mathrm{Au}$ & No & No & $100 \%$ & 0 & $\overline{0}$ & 0 & 170.5 & 6.4 \\
\hline & $\mathrm{Cr} / \mathrm{Au}$ & No & Yes & $100 \%$ & 0 & 0 & 0 & 137.7 & 3.9 \\
\hline & $\mathrm{Cr} / \mathrm{Au}$ & Yes & No & 0 & 0 & $100 \%$ & 0 & 0 & 0 \\
\hline & $\mathrm{Cr} / \mathrm{Au}$ & Yes & Yes & 0 & $80 \%$ & $20 \%$ & 0 & 127.5 & 33.5 \\
\hline & $\mathrm{Ti} / \mathrm{TiN} / \mathrm{Pt} / \mathrm{Au}$ & No & No & $100 \%$ & 0 & 0 & 0 & 191.8 & 6.5 \\
\hline & $\mathrm{Ti} / \mathrm{TiN} / \mathrm{Pt} / \mathrm{Au}$ & No & Yes & $84 \%$ & $16 \%$ & 0 & 0 & 181.6 & 11.8 \\
\hline & $\mathrm{Ti} / \mathrm{TiN} / \mathrm{Pt} / \mathrm{Au}$ & Yes & No & $100 \%$ & 0 & 0 & 0 & 180.4 & 3.9 \\
\hline & $\mathrm{Ti} / \mathrm{TiN} / \mathrm{Pt} / \mathrm{Au}$ & Yes & Yes & $100 \%$ & 0 & 0 & 0 & 179.9 & 5.6 \\
\hline \multirow{8}{*}{$\begin{array}{l}\text { After } \\
\text { Temp. } \\
\text { Cycle }\end{array}$} & $\mathrm{Cr} / \mathrm{Au}$ & No & No & $100 \%$ & 0 & 0 & 0 & 155.7 & 8.3 \\
\hline & $\mathrm{Cr} / \mathrm{Au}$ & No & Yes & $100 \%$ & 0 & 0 & 0 & 147.4 & 7.4 \\
\hline & $\mathrm{Cr} / \mathrm{Au}$ & Yes & No & 0 & 0 & $100 \%$ & 0 & 0 & 0 \\
\hline & $\mathrm{Cr} / \mathrm{Au}$ & Yes & Yes & 0 & $80 \%$ & $20 \%$ & 0 & 79.5 & 48.8 \\
\hline & $\mathrm{Ti} / \mathrm{TiN} / \mathrm{Pt} / \mathrm{Au}$ & No & No & $76 \%$ & $6 \%$ & 0 & $18 \%$ & 190.2 & 7.2 \\
\hline & $\mathrm{Ti} / \mathrm{TiN} / \mathrm{Pt} / \mathrm{Au}$ & No & Yes & $78 \%$ & $10 \%$ & 0 & $12 \%$ & 185.2 & 7.4 \\
\hline & $\mathrm{Ti} / \mathrm{TiN} / \mathrm{Pt} / \mathrm{Au}$ & Yes & No & $97 \%$ & $3 \%$ & 0 & 0 & 191.8 & 6.5 \\
\hline & $\mathrm{Ti} / \mathrm{TiN} / \mathrm{Pt} / \mathrm{Au}$ & Yes & Yes & $97 \%$ & 0 & 0 & $3 \%$ & 182.9 & 11.1 \\
\hline
\end{tabular}

TABLE IV

ANOVA TABle For Mean PUll StRENGTH

\begin{tabular}{|l|l|l|l|l|l|}
\hline Source & Sum of Squares & Df & Mean Square & F-Ratio & P-value \\
\hline Main effect & & & & & \\
\hline A: Metallization & 27680.6 & 1 & 27680. & 30.31 & 0.002 \\
\hline B: Annealing & 10925.5 & 1 & 10925. & 11.96 & 0.018 \\
\hline C: CAN etch & 1247.86 & 1 & 1247.8 & 1.37 & 0.30 \\
\hline D: Temp-cycling & 84.18 & 1 & 84.18 & 0.09 & 0.77 \\
\hline Interactions & & & & & \\
\hline AB & 9530.6 & 1 & 9530.6 & 10.44 & 0.02 \\
\hline AC & 2268.1 & 1 & 2268.1 & 2.48 & 0.18 \\
\hline AD & 301.89 & 1 & 301.89 & 0.33 & 0.59 \\
\hline BC & 40229.1 & 1 & 40229.1 & 4.41 & 0.09 \\
\hline BD & 58.14 & 1 & 58.14 & 0.06 & 0.81 \\
\hline CD & 44.56 & 1 & 44.56 & 0.05 & 0.83 \\
\hline Residual & 4566.37 & 5 & 913.27 & & \\
\hline Total (Corrected) & 60737.0 & 15 & & & \\
\hline
\end{tabular}

bonding performance indicating that there was not much contamination on the wafer surface in this experiment.

\section{B. Experiment 2}

It is clear from the results of the previous experiment, that both $\mathrm{Cr}-\mathrm{Au}$ and $\mathrm{Ti}-\mathrm{TiN}-\mathrm{Pt}-\mathrm{Au}$ metallization systems are acceptable for a $25.4 \mu \mathrm{m} \times 254 \mu \mathrm{m}(1 \mathrm{mil} \times 10 \mathrm{mil})$ ribbon bonding process. The purpose of the second experiment was to determine if an additional wafer annealing process has a detrimental effect on ribbon bonding performance. The purpose of the annealing process is to stabilize the metallization system. In this experiment, the annealing process added during wafer fabrication was a $400{ }^{\circ} \mathrm{C}$ air bake for $30 \mathrm{~min}$ to pronounce the effect.

The second experiment was split into 16 cells as illustrated in Fig. 2. The two metallizations each had one annealed and one

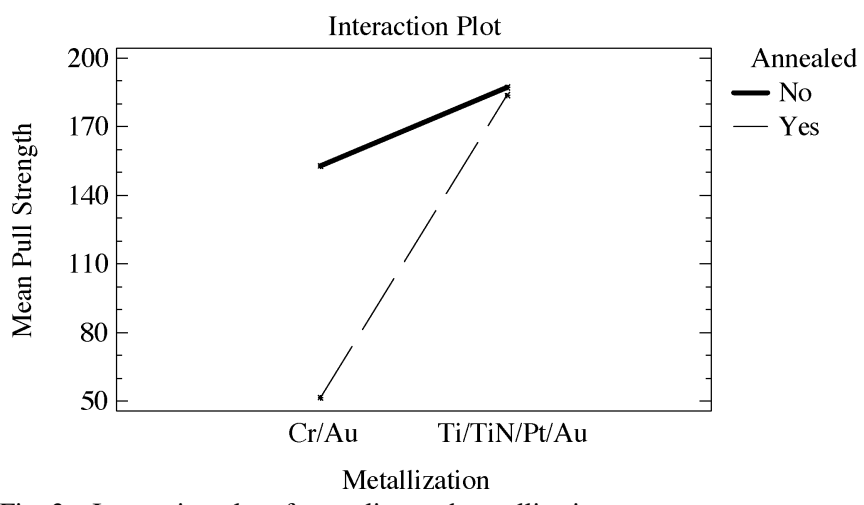

Fig. 3. Interaction plot of annealing and metallization.

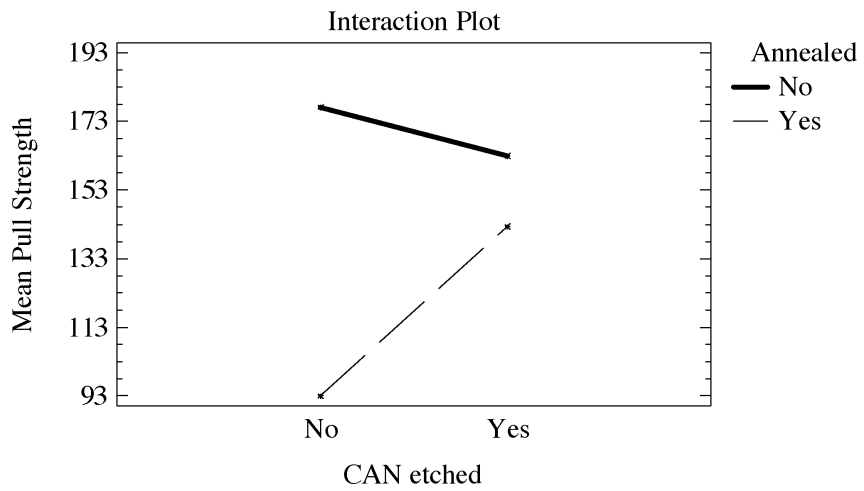

Fig. 4. Interaction plot of annealing and CAN etch.

nonannealed sample with each of these being with or without CAN etch. After ribbon bonding, half of the bonds were pulled 


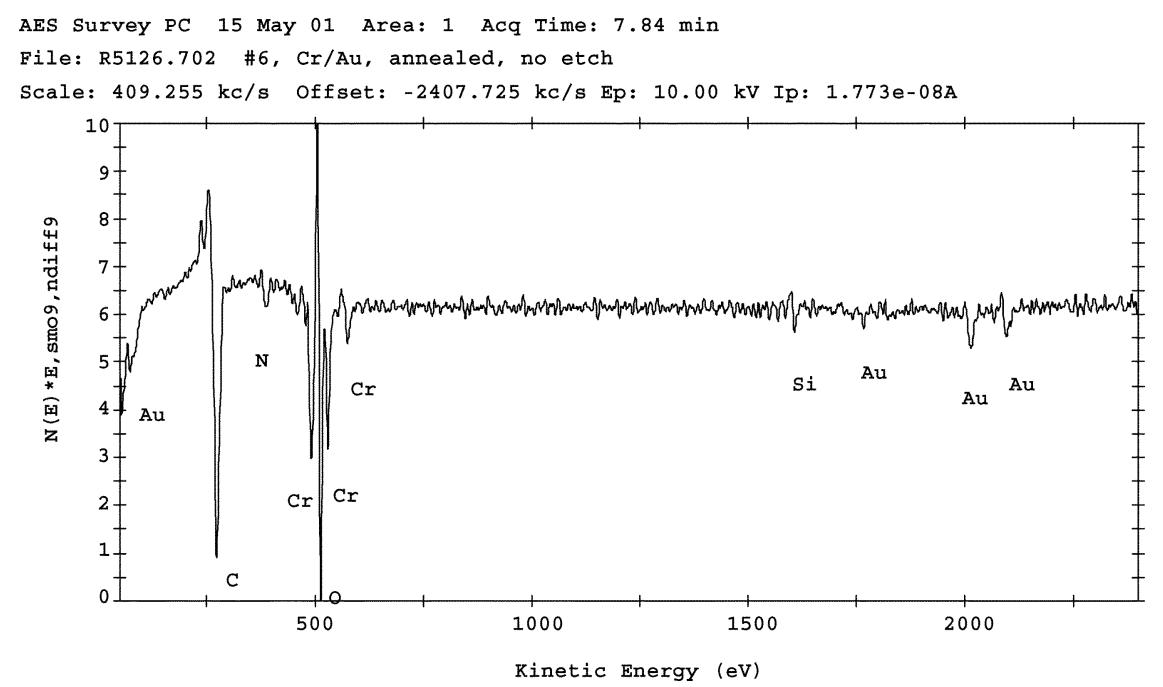

Fig. 5. AES surface surveys for annealed no CAN-etched $\mathrm{Cr}-\mathrm{Au}$ wafer.

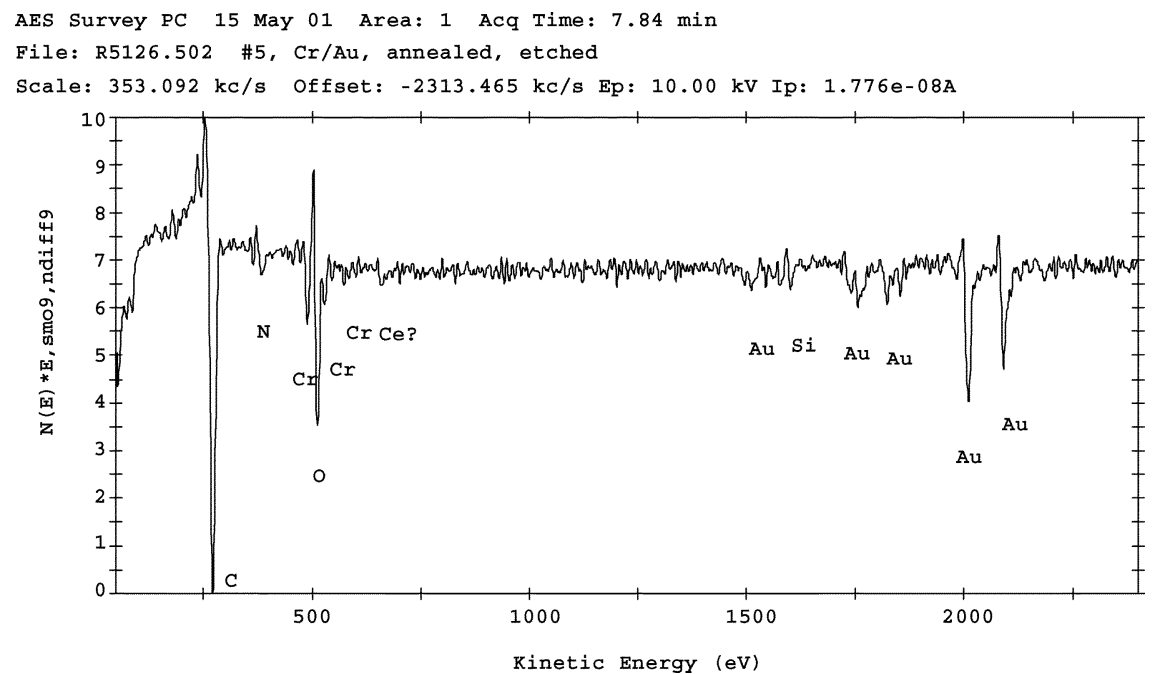

Fig. 6. AES surface surveys for annealed CAN-etched $\mathrm{Cr}-\mathrm{Au}$ wafer.

immediately and half were pulled after the temperature cycling of $0{ }^{\circ} \mathrm{C}-85^{\circ} \mathrm{C}$ for four cycles.

The CAN etch time used in this experiment was $1 \mathrm{~min}$. The solution for CAN etch consists of $65 \%-75 \%$ water, $20 \%-30 \%$ ceric ammonium nitride, and $1 \%-5 \%$ acetic acid. In addition, all of the samples received the 10-min UV ozone cleaning after the CAN etch.

All bonding parameters and loop parameters were the same as in Experiment 1 except the ultrasonic power increased from 60 to 65 . The purpose of the change was to eliminate the footlift failure mode. Some gold peel-off was observed on annealed wafers with $\mathrm{Cr}-\mathrm{Au}$ metallization during dicing.

The pull strengths and failure modes are summarized in Table III. The data show that the failure mode for bonds on annealed $\mathrm{Cr}-\mathrm{Au}$ metallization before the $\mathrm{CAN}$ etch was $100 \%$ nonstick, which means that no bond was able to be made. Although different bonding parameter combinations were tried to improve bonding performance, nonstick still remained the dominant failure modes on annealed $\mathrm{Cr}-\mathrm{Au}$ metallization before the CAN etch. Even maximum ultrasonic power that could be offered by the bonder was unable to make bonds stick. CAN etch improved bondability slightly and switched the dominant failure mode from nonstick to foot lift.

\section{Data Analysis}

The data were analyzed using analysis of variance (ANOVA). The ANOVA Table for the average pull strength is shown in Table IV. It shows that metallization and annealing have statistically significant effects on the mean pull strength and strong interaction exists between metallization and annealing. The interaction plot of metallization and annealing in Fig. 3 shows that annealing has significant effect on $\mathrm{Cr}-\mathrm{Au}$ metallization, but not for Ti-TiN-Pt-Au metallization. The bondability of $\mathrm{Cr}-\mathrm{Au}$ degraded dramatically after the wafers were annealed. The ANOVA analysis in Table IV also shows that CAN etch and temperature cycles do not have statistically significant effect on mean pull strength. There is interaction between annealing and CAN etch at $90 \%$ confidence level. The interaction plot of annealed and CAN etch is shown in Fig. 4. Table III shows that $\mathrm{CAN}$ etch improved the ribbon bond pull strength on annealed $\mathrm{Cr}-\mathrm{Au}$ metallization. However, the failure mode is $80 \%$ foot-lift and $20 \%$ nonstick, which is not acceptable for good 
TABLE V

AugER SuRfaCe ANALYSIS RESUlts

\begin{tabular}{|l|c|c|c|c|c|}
\hline Metallization & Annealed & $\begin{array}{c}\text { CAN } \\
\text { etched }\end{array}$ & $\begin{array}{c}\text { Elements detected } \\
\text { except C, O, N, Au }\end{array}$ & Cr/Au ratio & C/Au ratio \\
\hline $\mathrm{Cr} / \mathrm{Au}$ & No & No & None & -- & 1.3 \\
\hline $\mathrm{Cr} / \mathrm{Au}$ & No & Yes & None & -- & 2.5 \\
\hline $\mathrm{Cr} / \mathrm{Au}$ & Yes & No & $\mathrm{Cr}$ & 3.7 & 7.8 \\
\hline $\mathrm{Cr} / \mathrm{Au}$ & Yes & Yes & $\mathrm{Cr}$ & 0.3 & 2.8 \\
\hline $\mathrm{Ti} / \mathrm{TiN} / \mathrm{Pt} / \mathrm{Au}$ & No & No & None & -- & 3.2 \\
\hline $\mathrm{Ti} / \mathrm{TiN} / \mathrm{Pt} / \mathrm{Au}$ & No & Yes & None & -- & 4.0 \\
\hline $\mathrm{Ti} / \mathrm{TiN} / \mathrm{Pt} / \mathrm{Au}$ & Yes & No & None & -- & 1.2 \\
\hline $\mathrm{Ti} / \mathrm{TiN} / \mathrm{Pt} / \mathrm{Au}$ & Yes & Yes & None & -- & 1.1 \\
\hline
\end{tabular}

AES Profile PC Alt. 15 May 01 Region: 4(Si2) Area: 1 Sput Time: $33.50 \mathrm{~min}$

File: R5126.600 \#6, $\mathrm{Cr} / \mathrm{Au}$, annealed, no etch

Scale: $1130.410 \mathrm{kc} / \mathrm{s}$ Offset: $70.400 \mathrm{kc} / \mathrm{s}$ Ep: $10.00 \mathrm{kV}$ Ip: $2.169 \mathrm{e}-08 \mathrm{~A}$

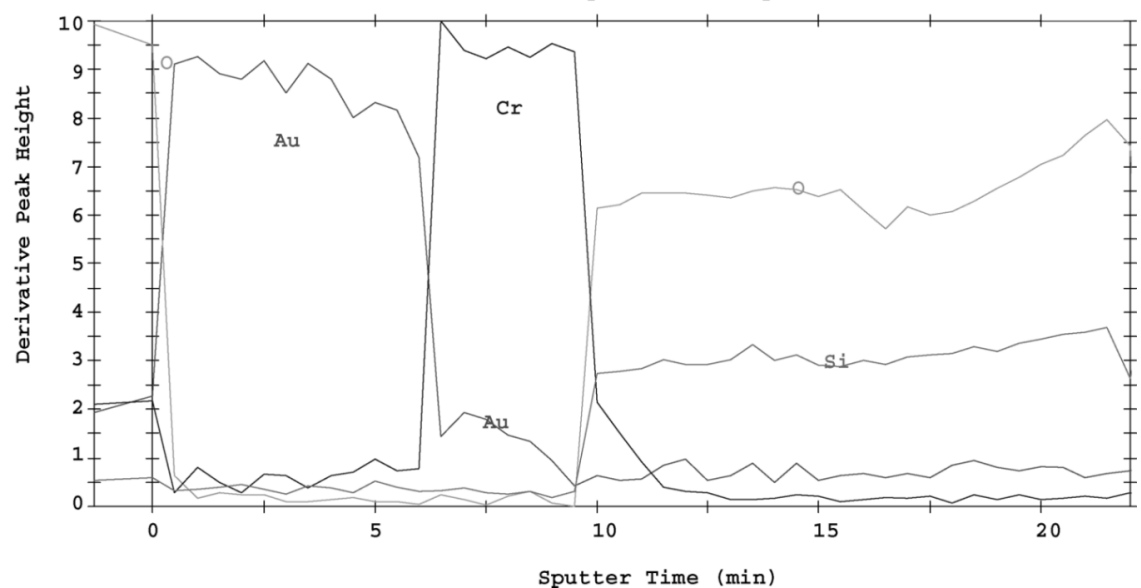

Fig. 7. AES profile for annealed no $\mathrm{CAN}-$ etched $\mathrm{Cr}-\mathrm{Au}$.

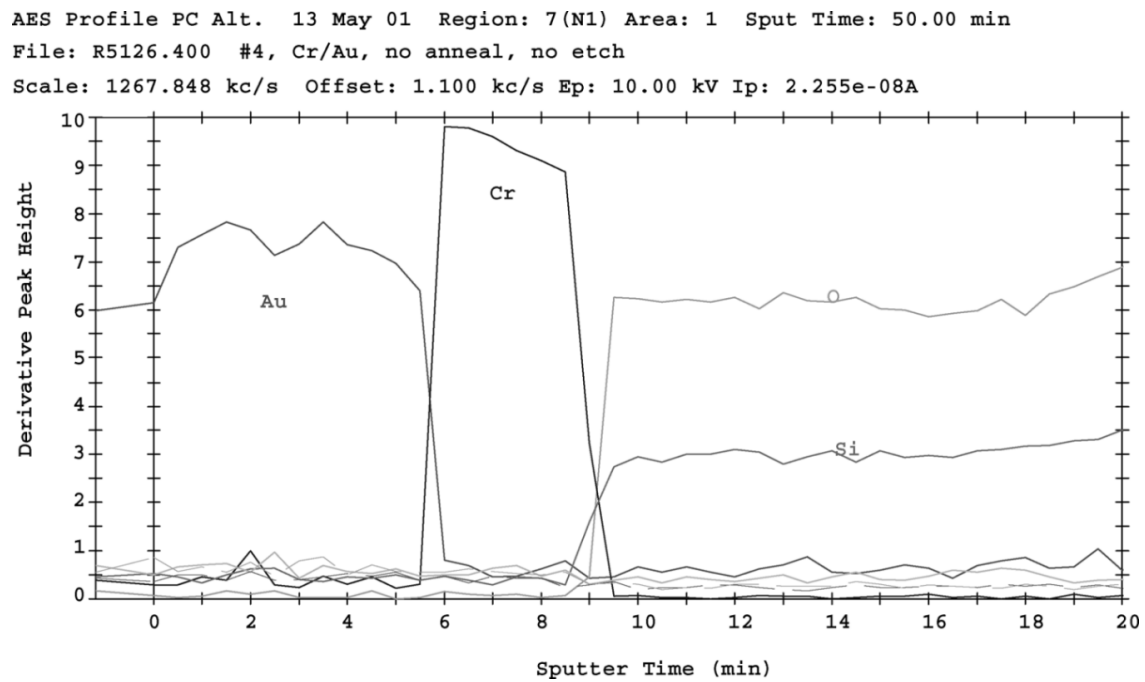

Fig. 8. AES profile for no annealed no CAN-etched $\mathrm{Cr}-\mathrm{Au}$.

wire/ribbon bondability. The investigation of the experimental phenomena is described in the next section. ANOVA analysis shows that temperature cycling does not significantly degrade $\mathrm{Au}-\mathrm{Au}$ ribbon bonds.

\section{RESUlTS AND DISCUSSION}

To further investigate what caused the bondability difference between these two metallizations, auger electron spectroscopy (AES) was used to analyze all wafer surfaces. The AES surface survey for annealed no CAN-etched $\mathrm{Cr}-\mathrm{Au}$ wafer is illustrated in Fig. 5 and that for annealed CAN-etched $\mathrm{Cr}-\mathrm{Au}$ wafer is illustrated in Fig. 6. It is clearly shown that significant $\mathrm{Cr}$ was present on annealed no CAN-etched wafer and the $\mathrm{Cr}$ contamination level was reduced after CAN etch. The AES surface analysis results are summarized in Table V. Chromium was detected on annealed $\mathrm{Cr}-\mathrm{Au}$ metallization, and the chromium-gold ratio decreased from 3.7 to 0.3 after CAN etch for 1 min. Panousis and Bonham [2] reported that no chromium was detected after CAN etch for $10 \mathrm{~min}$. This implies that the CAN etch time in this 


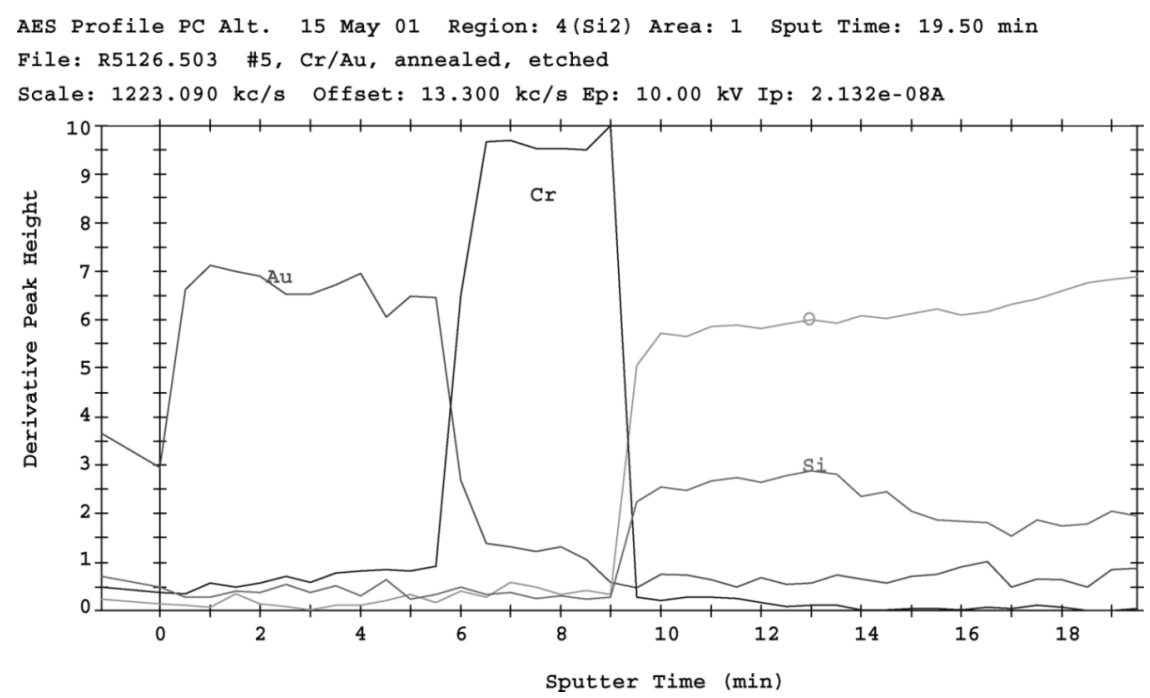

Fig. 9. AES profile for annealed $\mathrm{CAN}$-etched $\mathrm{Cr}-\mathrm{Au}$.

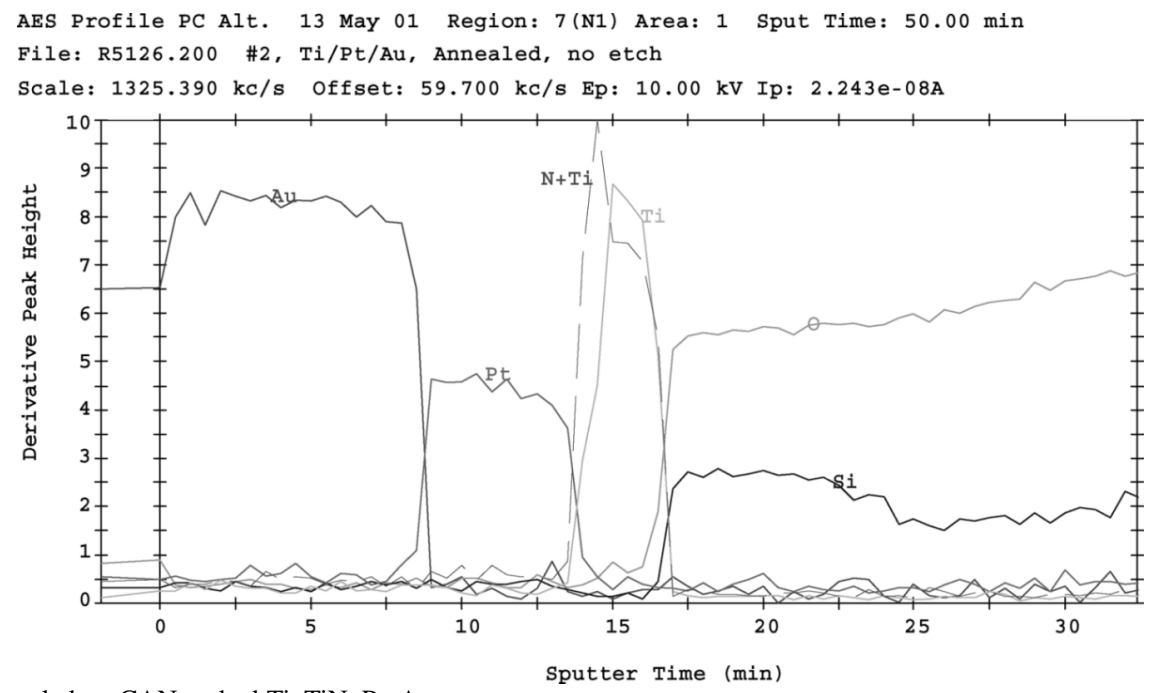

Fig. 10. AES profile for annealed no CAN-etched Ti-TiN-Pt-Au.

experiment was not long enough to eliminate the surface $\mathrm{Cr}$ contamination. Increasing etch time should remove all chromium and chromium oxide on the gold surface. It was expected that the amount of chromium diffusing on the gold surface would increase with higher annealing temperature, longer annealing time, and thinner gold thickness. Therefore, CAN etch time, for manufacturing purposes, should be determined according to the annealing process (annealing temperature and annealing time) and the gold thickness.

To find the CAN etch time, it is necessary to know the diffusion rate. An understanding of the diffusion mechanism is important to determine the diffusion rate. The possible mechanisms of $\mathrm{Cr}$ diffusion to Au surface include grain boundary, dislocation pipes, bulk diffusion, and surface diffusion [10]. Thomas and Hass [10] reported that the diffusion rate for $\mathrm{Cr}$ into $\mathrm{Au}$ films in thin-film system, where dislocation pipes is the dominant diffusion mechanism, depends on the Au film deposition rates. Huang et al. [11] observed $\mathrm{Cr}$ diffused markedly into Au layer when annealed at $200^{\circ} \mathrm{C}$ for $30 \mathrm{~min}$ or $250^{\circ} \mathrm{C}$ for $5 \mathrm{~min}$. The specific metallization they used was 110 -nm-thick $\mathrm{Au}$ on 20-nm-thick $\mathrm{Cr}$ layer. The mechanism of $\mathrm{Cr}$ diffusion was not documented in their paper. Weinman et al. [12] derived the grain boundary diffusion coefficient for $\mathrm{Cr}$ in $\mathrm{Au}$ at $300^{\circ} \mathrm{C}$ is $4 \times 10^{-15} \mathrm{~cm}^{2} \mathrm{~s}^{-1}$. However, the grain boundary diffusion coefficient for $\mathrm{Cr}$ in $\mathrm{Au}$ at $400{ }^{\circ} \mathrm{C}$ could not be found from published literature.

To determine why Au peeled off from annealed $\mathrm{Cr}$-Au wafers during dicing, AES was used to do ion sputtered depth profiles, which is an analytical technique capable of identifying elemental concentration profiles. Ion sputtered depth profile of annealed no CAN-etched $\mathrm{Cr}-\mathrm{Au}$ wafer is shown in Fig. 7 and that of no annealed no CAN-etched $\mathrm{Cr}-\mathrm{Au}$ wafer is shown in Fig. 8. Note that $\mathrm{Au}$ was found in the $\mathrm{Cr}$ layer (1.5-2 units of Au and 10 units of $\mathrm{Cr}$ in Fig. 7) of the annealed $\mathrm{Cr}-\mathrm{Au}$ metallization and little $\mathrm{Au}$ was found in $\mathrm{Cr}$ layer (0.5 units of $\mathrm{Au}$ and 10 units of $\mathrm{Cr}$ in Fig. 8) of nonannealed samples. For comparison, ion sputtered depth profiles of annealed CAN-etched $\mathrm{Cr}-\mathrm{Au}$ is shown in Fig. 9. The function of chromium in the metallization is to promote adhesion between the substrate and the sputtered gold film. The fact that Au diffused to the Cr layer may be the reason that Au peeled off during dicing.

Another possibility that caused Au peeled off could be the chromium oxides under the gold results in a weakened adhesion of the Au film. Since the annealing process was performed 
in the air, oxygen can diffuse into the Au layer and form $\mathrm{Cr}_{2} \mathrm{O}_{3}$ under the Au layer. Weinman et al. [12] detected the presence of oxygen throughout the gold layer using a depth profile and confirmed the $\mathrm{Cr}$ remaining in the grain boundaries was oxidized using X-ray photoelectron spectroscopy (XPS). The metallization they used was $200 \AA$ of chromium on $1000 \AA$ of gold.

The C/Au ratio is one of the ways to determine the organic contamination level on Au surface. The higher the C/Au ratio means more organic contamination on gold surface. Table $\mathrm{V}$ shows that the no-annealed Ti-TiN-Pt-Au wafers have higher $\mathrm{C} / \mathrm{Au}$ ratio than that with annealed. This could explain why the no-annealed Ti-TiN-Pt-Au wafers have more foot lift bonds than the annealed ones.

Ti was not detected either on nonannealed or on annealed samples. That means that Ti diffusion was blocked by the TiN layer or the Pt layer. Fig. 10 shows the Ion sputtered depth profile of annealed no CAN-etched Ti-TiN-Pt-Au. That is why annealing at $400{ }^{\circ} \mathrm{C}$ for $30 \mathrm{~min}$ does not degrade ribbon bondability of Ti-TiN-Pt-Au metallization.

\section{CONCLUSION}

The following conclusions can be drawn based on this study.

1) Without annealing, both $\mathrm{Cr}-\mathrm{Au}$ and $\mathrm{Ti}-\mathrm{TiN}-\mathrm{Pt}-\mathrm{Au}$ metallization systems have good wire/ribbon bondability.

2) The ribbon bonding performance degraded dramatically on $\mathrm{Cr}-\mathrm{Au}$ wafers after they were annealed at $400{ }^{\circ} \mathrm{C}$ for 30 min. CAN etch for 1 min partially removed $\mathrm{Cr}$ oxide on Au surfaces. A longer time could restore the bondability for $\mathrm{Cr}-\mathrm{Au}$ metallization.

3) Annealing at $400{ }^{\circ} \mathrm{C}$ for 30 min does not degrade ribbon bondability of Ti-TiN-Pt-Au metallization.

4) Temperature cycling from $0{ }^{\circ} \mathrm{C}$ to $85^{\circ} \mathrm{C}$ with four cycles does not degrade Au wire/ribbon to Au metallization bonds.

\section{ACKNOWLEDGMENT}

The authors would like to thank J. Shearer for the Auger analysis, L. Gomez and J. Bailey for preparing metallized samples, R. Liddick and B. Hayes for ribbon bonding and pull testing, and R. Kershner for valuable discussions. The authors would also like to thank the technical reviewers for invaluable comments.

\section{REFERENCES}

[1] G. Harman, Wire Bonding in Microelectronics: Material, Processes, Reliability and Yield, 2nd ed. New York: McGraw-Hill, 1997, pp. 68-69, 171-178.

[2] N. T. Panousis and H. B. Bonham, "Bonding degradation in the tantalum nitride-chromium-gold metallization system," in Proc. 11th Annu. Rel. Phys. Conf., Las Vegas, NV, 1973, pp. 21-25.

[3] P. H. Holloway and R. L. Long, "On chemical cleaning for thermocompression bonding," IEEE Trans. Parts, Hybrids, Packag., vol. PHP-11, no. 2, pp. 83-88, Jun. 1975.

[4] T. C. Tisone and J. Drobek, "Diffusion in thin film Ti-Au, Ti-Pd, and Ti-Pt couples," J. Vac. Sci. Technol., vol. 9, no. 1, pp. 271-275, 1972.

[5] K. Masahiro and S. Noboru, "Effects of temperature, thickness and atmosphere on mixing in Au-Ti bilayer thin films," J. Mater. Sci., vol. 28, no. 18, pp. 5088-5091, Sep. 15, 1993.
[6] A. Sozza, C. Dua, A. Kerlain, C. Brylinski, and E. Zanoni, "Long-term reliability of Ti-Pt-Au metallization system for Schottky contact and first-level metallization on SiC MESFET," Microelectron. Rel., vol. 44 no. 7, pp. 1109-1113, Jul. 2004.

[7] W. J. Garceau, P. R. Fournier, and G. K. Herb, "TiN as a diffusion barrier in the Ti-Pt-Au beam-lead metal system," Thin Solid Films, vol. 60, no. 2, pp. 237-247, Jun. 15, 1979.

[8] R. J. Thompson, D. R. Cropper, and B. W. Whitaker, "Bondability problems associated with the Ti-Pt-Au metallization of hybrid microwave thin film circuits," IEEE Trans. Compon., Hybrids, Manuf. Technol., vol. CHMT-4, no. 4, pp. 439-445, Dec. 1981.

[9] R. Rodwell and D. A. Worrall, "Quality control in ultrasonic wire bonding," Int. J. Hybrid Microelectron., vol. 8, no. 2, pp. 1-8, Jun. 1985.

[10] R. E. Thomas and G. A. Haas, "Diffusion measurements in thin films utilizing work function changes: Cr into Au," J. Appl. Phys., vol. 43, no. 12, pp. 4900-4907, Dec. 1972.

[11] Y. Huang, H. Qiu, F. Wang, L. Pan, Y. Tian, and P. Wu, "Effect of annealing on the characteristics of Au/Cr bilayer films grown on glass," Vacuum, vol. 71, no. 4, pp. 523-528, Jul. 25, 2003.

[12] L. S. Weinman, T. W. Orent, and T. S. Liu, "Auger study of $\mathrm{Cr}-\mathrm{Au}$ thin films deposited on alumina and sapphire," Thin Solid Films, vol. 72, no. 1, pp. 143-149, Sep. 15, 1980.

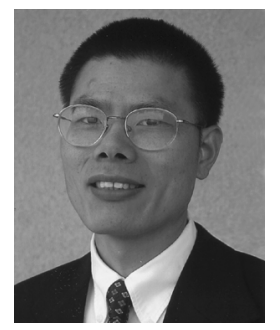

Jianbiao Pan (M'03) received the B.E. degree in mechatronics from Xidian University, Xian, China, in 1990, the M.S. degree in manufacturing engineering from Tsinghua University, Beijing, China, in 1996, and the Ph.D. degree in industrial engineering from Lehigh University, Bethlehem, PA, in 2000.

$\mathrm{He}$ is an Assistant Professor in the Department of Industrial and Manufacturing Engineering, California Polytechnic State University (Cal Poly), San Luis Obispo, CA. Prior to joining Cal Poly, he worked at the Optoelectronics Center of Lucent Technologies/Agere Systems as Member of Technical Staff. His research interests are in microelectronics packaging, electronics assembly, lead-free soldering, design of experiments, and statistical process control.

Dr. Pan is a senior member of SME and IMAPS, a member of Sigma Xi. He is a recipient of the $2004 \mathrm{M}$. Eugene Merchant Outstanding Young Manufacturing Engineer Award from SME.

Robert M. Pafchek, photograph and biography unavailable at the time of publication.

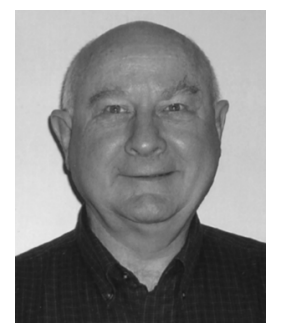

Frank F. Judd received the B.S. and M.S. degrees in electrical engineering from Brigham Young University, Provo, UT, in 1961 and 1962, respectively, and the $\mathrm{Ph} . \mathrm{D}$. degree in electrical engineering from the Stevens Institute of Technology, Hoboken, NJ, in 1973.

In 1962, he joined AT\&T Bell Laboratories as a Member of Technical Staff, and in 1984 was promoted to Distinguished Member of Technical Staff. He has worked in the areas of electronic power systems and magnetic bubble memory design, before being promoted to Supervisor of the Photonics Packaging Research Group. Before retiring from Agere Systems in 2002, He managed a team of engineers responsible for the design and development of lithium niobate integrated optic devices for high-speed optical telecommunications.

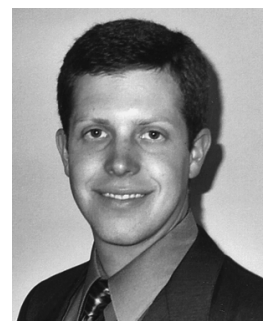

Jason B. Baxter received the B.Ch.E. degree in chemical engineering from the University of Delaware, Newark, in 2000, and the Ph.D. degree in chemical engineering from the University of California, Santa Barbara, in 2005.

Currently, he is a Postdoctoral Fellow in the Chemistry Department, Yale University, New Haven, CT, and he will begin as an Assistant Professor of chemical engineering at Drexel University, Philadelphia, PA, in 2007. His research interests are in the growth of wide-band gap semiconductor nanostructures and their use in renewable energy applications. 